\title{
ÜÇ FAZLI ASENKRON MOTORLARDAKİ KIRIK ROTOR ÇUBUĞU ARIZALARININ TESPİTİ İÇİN GÜÇ TABANLI BİR ALGORITTMANIN GELİŞTİRİLMESİ
}

\author{
Mehmet BAYRAK, Ahmet KÜÇÜKER \\ Sakarya Üniversitesi, Mühendislik Fakültesi, Elektrik-Elektronik Mühendisliği Bölümü, Sakarya \\ bayrak@sakarya.edu.tr, kucuker@sakarya.edu.tr
}

(Geliş/Received: 19.02.2015; Kabul/Accepted: 24.07.2015)

ÖZET

Üç fazlı asenkron motorlarda herhangi bir arıza durumunda veya dengesiz kaynakla beslendiklerinde çekilen güçte şebeke frekansından farklı frekanslarda birçok sinüsoidal bileşen ortaya çıkmaktadır. Bu bileşenlerin genliği ve frekansı, oluşan arızalar ve derecesi hakkında bilgi verir. Kırı rotor çubuğu arızalarında özellikle şebeke frekansının iki katı frekansın her iki yanında kaymaya bağlı olarak bileşenlerin belirgin olarak arttığı teorik analizler sonucunda görülmüştür. Geliştirilen kırık rotor çubuğu arızası tespit yöntemi motorun çektiği üç fazlı ani güçteki $90-110 \mathrm{~Hz}$ frekans aralığındaki bileşenlerin enerji yoğunluğu değişimi temeline dayanmaktadır. Yapılan deneysel çalışmalarla yeni geliştirilen arıza tespit yönteminin diğer yöntemlerden daha güvenilir ve etkin çalıştı̆̆ görülmüştür.

Anahtar Kelimeler: Asenkron motorlar, kırık rotor çubuğu arızası, motor ani gücü

\section{A POWER BASED ALGORITHM DESIGN FOR DETECTION OF BROKEN ROTOR BARS FAULTS IN THREE PHASE INDUCTION MOTORS}

\begin{abstract}
Many sinusoidal components different from power system frequency in instantaneous power occur in three phase induction motors during faults and unbalanced conditions. The amplitude and frequency of these components give an idea about faults and their level. Theoretical analysis indicates that side band components that changes with slip around twice of the power system frequency occur during broken rotor bars faults. The new detection algorithm that introduced is based on power spectral density changes between $90-110 \mathrm{~Hz}$ frequency band in three phase instantaneous power. Experimental results have demonstrated that the new algorithm detects the faults more reliable and effective than the other methods.
\end{abstract}

Keywords: Induction motors, broken rotor bar faults, motor instantaneous power

\section{GİRIŞ (INTRODUCTION)}

Asenkron motorlar endüstrinin birçok alanında yaygın olmakla birlikte, özellikle kimya ve petrokimya gibi karmaşık endüstriyel tesislerde uzun yıllardan beri kullanılmaktadır. $\mathrm{Bu}$ tür tesislerde elektrik motorları kritik öneme sahiptir ve oluşabilecek arızalarda tesis durmasının getireceği zararlara ilave olarak önemli miktarda hammadde kaybı da oluşmaktadır. Bu nedenle, asenkron motorlardaki arızaların endüstriyel tesisi durduracak kadar önemli bir noktaya gelmeden önce tespit edilmesi çok önemlidir. Asenkron motorlardaki arızalar genellikle stator sarg1 kısa devreleri, rotor arızaları, rulman arızaları veya dengesiz gerilimden dolayı oluşan arızalar olarak dört farklı gruba ayrılabilir. Stator arızaları genellikle yalıtımdaki bozulmalar veya yaşlanmalar ile geçici aşırı gerilimler ile mekanik titreşimler sonucunda yalıtımın zarar görmesi sonucu sarım kısa devresi veya toprak kısa devresi biçiminde oluşmaktadır. Rotor arızaları çalışma sırasındaki yüksek sıcaklıktan veya özellikle kalkış gibi geçici mekanik darbelerden dolayı oluşmaktadır. Yapılan araştırmalar göstermiştir $\mathrm{ki}$, asenkron motor arızalarının yaklaşı \%5-10'unu rotor arızaları oluşturmaktadır [1]. Motorlardaki arızaları veya anormal çalışma durumlarını tespit 
etmek amacıyla titreşim ve sıcaklık algılayıcıları, hava aralığındaki akı yoğunluğu algılayıcıları, rotor pozisyon ile hız algılayıcıları ve çıkış momenti algılayıcıları kullanılmaktadır. Sıcaklık ve titreşim algılayıcılarının uzun yıllar kullanılmasına rağmen, ilave bir donanım gerektirmesi ve arızaları tespit etmede yetersiz olmaları sonucu artık kullanılmamaktadır. Rotor arızalarını tespit etmek için geliştirilen stator akımı imza analizi yönteminde, bir fazdan ölçülen stator akımının frekans spektrumundaki temel frekans bileşeninin yanındaki kaymaya bağlı olarak değișen yan bantlar $(1 \pm 2 \mathrm{~s}) \mathrm{f}$ gözlenmektedir [2-4]. Bu yönteme göre, arıza sırasında şebeke frekans bileşeninin yan taraflarında kayma frekansının iki katı frekansta oluşan bileşenin genliği rotordaki kırık sayısına göre orantılı olduğu belirtilmektedir [5-7]. Fakat değişken yükten veya herhangi bir mekanik bozucu etkiden dolayı motor momentindeki düşük frekanslı bileşenler de akımda kırık rotor çubuğu arızasının oluşturduğu bileşenleri meydana getirdiğinden, akım imza analizi tabanlı yöntemlerin arıa tespitindeki güvenilirliği azaltmaktadır [8]. Motor momentinde, dolayısıyla akımda oluşan bu bileşenler yük karakteristiğinden, mekanik dengesizlik veya dişli arızalarından kaynaklanabilir. Momentteki bu salınımların frekansı kayma frekansının iki katı frekansa yakın olduğu durumlarda kırık rotor çubuğu arızası varmış gibi görülebilir ve hatalı tespit edilmiş olur [9]. Ayrıca, motor yüksüz veya az yüklü olduğunda kayma çok küçük olacağından, akım spektrumunda yan bant bileşenleri görülemeyebilir. Bu sorunu çözmek için motorun kalkış sırasındaki akımının gözlenmesi ilkesine dayanan bir yöntem geliştirilmiştir [10]. Motorun kalkış anındaki kayması normal çalışma durumuna göre daha büyük olacağından, sürekli çalışma durumunda tespit edilemeyen kırık rotor çubuğu arızaları kestirilebilmektedir. Fakat bu yöntemin, motorun durdurulup tekrar çalıştırılması gerekliliği nedeniyle, sürekli çalışan motorlara uygulanması mümkün değildir. Mekanik arızalar ve dengesizlikler ile kırık rotor çubuğu arızasını birbirinden ayırmak için yapılan çalışmalar sonucunda akıllı hesaplama teknikleri olarak bilinen [11] bulanık mantık ve negatif seçim tabanlı bir algoritma geliştirilmiştir [12].

Motorun yüksüz olduğu durumdaki arızaları tespit etmek için Wavelet dönüşümü kullanılarak bazı yöntemler geliştirilmiştir [13-16]. Fakat bu yöntemler çok fazla matematiksel işlemler gerektirdiğinden, pratikte uygulanabilmesi için çok ileri düzeyde mikroişlemci tabanlı sistemlere gereksinim vardır. Asenkron motorların normal çalışması sırasında yük tarafindan kaynaklanan titreşimlerin oluşturduğu sorunları giderebilmek için stator akımlarından yükün tahmin edilmesiyle zamanla değişen yüklerin kestirilmesini amaçlayan çalışmada [17] sıcaklık ve diğer motor parametrelerin etkisi göz önüne alınmadığı için istenilen başarı sağlanamamıştır [18]. Değişken yüklerin akım imza analizinde oluşturduğu etki ile kırık rotor çubuğu arızasını birbirinden ayırmak için aktif ve reaktif güç ölçümüne dayanan bir yöntem geliştirilmiştir [19, 20]. Park dönüşümü kullanılarak rotor arızalarının yük momenti değişimlerinden ayrılması için geliştirilen yöntem [21-23] yük değişimlerine aşırı duyarlı olması nedeniyle yaygın olarak kullanılamamıştır. Ayrıca, stator akımlarının Park dönüşümü sonrası d-eksen ve q-eksen akımları elde edildikten sonra d-eksen akımına dalgacık dönüșümünün uygulandığı ve çözünürlüğü artırmak için ilave matematiksel işlemlerin yapıldığı yöntem çok fazla hesaplamalar gerektirmektedir [24]. Sürücü üzerinden beslenen asenkron motorlarda kırık rotor çubuğu arızalarını tespit etmek için motor akımı imza analizi ile fuzzy lojik mantığının birlikte kullanıldığı bazı yöntemler geliştirilmiştir [25, 26].

Üç fazlı stator akımlarının sıfır geçiş anını temel alarak geliştirilen yöntemde (ZCT) 2sf bileşeninin varlığı arızanın oluştuğunun bir göstergesi olmaktadır [27, 28]. Yükün değişken olduğu durumlarda ve mekanik arızalarda benzer bileşenler ortaya çıktığından, bu yöntemlerin böyle durumlardaki yanıtı araştırılmamıştır. Ayrıca, şebeke geriliminde her bir fazda bulunan harmoniklerin farklı olması durumunda bazı belirsizlikler ortaya çıkacaktır. Sadece titreşim verilerine dayalı yöntemlerin arıza tespitinde yetersiz kalması ve güncelliğini yitirmesiyle geçici durumdaki titreşim verileri kullanılarak arıza tespit yöntemi geliştirilmiştir [29]. Bu yöntemde motorun geçici durumlarına ait titreşim verilerinin analizi sonucu elde edilen verilerin zaman-frekans düzlemindeki harmonik bileşenleri ile karşılaştırılması sonucu arıza tespit edilmektedir. Motor kalkış anındaki akımın incelenmesi durumunda olduğu gibi, bu yöntemde de arızayı tespit etmek için geçici durum bilgileri gerekmektedir.

Üç fazlı asenkron motorlarda kırık rotor çubuğu arızalarını algılamak için geliştirilen güç tabanlı algoritmada, bir faza ait ani güçteki kayma frekansındaki frekans bileşeninin varlığı kontrol edilmektedir [30]. Geliştirilen bu yöntem sadece bir fazdan ölçüm bilgisi aldığından, yaygın olarak kullanılan stator akımı imza analizi yönteminden farklı değildir. Diğer bir güç tabanlı rotor çubuk arızası tespit yöntemi üç fazlı asenkron motorun ani gücündeki $\mathrm{f}_{\mathrm{b}}=2 \mathrm{sf}$ bileşeninin gözlenmesi esasına dayanmaktadır $[18,31,32]$. Yük tarafında oluşabilecek titreşimler veya mekanik dengesizliklerin ani güçte düşük frekanslı bileşenleri meydana getirmesi [33], rotor çubuk arızasını düşük frekans bileşeninin gözlenmesi temeline dayanan algoritmaların hatalı çalışmasına neden olacaktır. Kırık rotor çubuğu arızasının hava aralığ momentinde oluşturduğu ilave bileşenleri tespit etmek 
için sonlu elemanlar yöntemi kullanılarak [34] elektromanyetik analizler yapılmıştır. Simetrik bir kaynaktan beslenen asenkron motorun akımı da simetrik olacağından, bunun sonucunda da hava aralığındaki akı düzgün biçimde dağılır. Rotor çubuğunda kırık meydana geldiğinde hava aralığındaki magnetik akı asimetrik olur ve bu durum farklı frekanslarda moment bileşenlerinin oluşmasına ve motor uçlarındaki gerilimin dengesiz hale gelmesine neden olur $[35,36]$. Gerilimdeki bu bozulma sonucu modülasyon yapılmış gibi etki eden bileşenin varlığının ortaya çıkarılmasıyla arıza tespit yöntemlerinde farklı bir bakış açısı getirilmiştir. Kırık rotor çubuğu arızası sırasında gerilim dengesizliğinin bozulması motor ani gücünü de etkileyecektir. Motor ani gücünde oluşan bu etkilenme temel alınarak bu çalışmada, üç fazlı asenkron motorlardaki rotor çubuk arızalarını tespit etmek amacıyla güç tabanlı bir algoritma geliştirilecektir. Rotor çubuğunda meydana gelen arızaların ani güçte oluşturacağı bileşenler matematiksel olarak bulunup, daha sonra bu bileşenlerin varlığına dayanan yeni bir arıza tespit algoritması geliştirilip test edilecektir.

\section{ROTOR ARIZALARININ ANI GÜCE ETKISİ (THE EFFECTS OF ROTOR FAULTS TO INSTANTANEOUS POWER)}

Dengeli üç fazlı gerilim kaynağından bir asenkron motorun çektiği güç aşağıda denklem 1'de verilen bağıntıyla ifade edilebilir.

$p(t)=v_{a} i_{a}+v_{b} i_{b}+v_{c} i_{c}=3 V \operatorname{Icos}(\varphi)=P$

Buradaki $v_{a}, v_{b}, v_{c}$ ve $i_{a}, i_{b}, i_{c}$ sirasıyla herbir fazın gerilim ile akımın aşağıda belirtilen ani değerlerini göstermektedir ve ifadeleri denklem 2 ve denklem 3 'te verilmiştir.

$v_{a}(t)=\sqrt{2} V \cos (\omega t)$

$v_{b}(t)=\sqrt{2} V \cos \left(\omega t-120^{\circ}\right)$

$v_{c}(t)=\sqrt{2} V \cos \left(\omega t+120^{\circ}\right)$

$i_{a}(t)=\sqrt{2} \operatorname{Icos}(\omega t-\varphi)$

$i_{b}(t)=\sqrt{2} \operatorname{Icos}\left(\omega t-\varphi-120^{\circ}\right)$

$i_{c}(t)=\sqrt{2} \operatorname{Icos}\left(\omega t-\varphi+120^{\circ}\right)$

Yukarıdaki ani güç bağıntısından da görüldüğü gibi, dengeli gerilim kaynağından beslenen üç fazlı asenkron motorun çektiği gücün ani değeri sabit olup, salınım yapmamaktadır. Herhangi bir arıza durumunda motor hava aralığındaki akı değişmesinden dolayı faz akımlarının genlikleri aşağıda denklem 4'te belirtildiği gibi farklı olacaktır

$i_{a}(t)=\sqrt{2} I_{a} \cos (\omega t-\varphi)$

$i_{b}(t)=\sqrt{2} I_{b} \cos \left(\omega t-\varphi-120^{\circ}\right)$

$i_{c}(t)=\sqrt{2} I_{c} \cos \left(\omega t-\varphi+120^{\circ}\right)$
Stator faz akımlarının genliklerinin farklı olması sonucu motorun çektiği ani güç denklem 5'teki gibi olacaktır [37].

$p(t)=v_{a} i_{a}+v_{b} i_{b}+v_{c} i_{c}=P+P_{2 m}(2 \omega t+\beta)$

olacaktır [37]. Arıza sırasında stator hava aralığının ters yönde dönen bileşenden dolayı ani güçte şebeke frekansının iki katı frekansta bir bileşen meydana gelmektedir. Dolayısıyla, motorun çektiği ani güçteki şebeke frekansının iki katı frekanstaki bileşenin genliği bir arıza göstergesi kabul edilmektedir.

Asenkron motorlarda rotor çubuğunun kırılması sonucunda stator akımları denklem 6'da verilen bağıntılarla ifade edilebilir [38].

$i_{a, b}(t)=$

$i_{a}(t)+\sum_{k=1}^{\infty}\left\{\begin{array}{c}\sqrt{2} I_{l k} \cos \left[\left(\omega-k \omega_{r}\right) t-\varphi_{l k}\right] \\ +\sqrt{ } 2 I_{r k} \cos \left[\left(\omega+k \omega_{r}\right) t-\varphi_{r k}\right]\end{array}\right\}$

$i_{b, b}(t)=$

$i_{b}(t)+$

$\sum_{k=1}^{\infty}\left\{\begin{array}{c}\sqrt{2} I_{l k} \cos \left[\left(\omega-k \omega_{r}\right) t-\varphi_{l k}-120^{\circ}\right] \\ +\sqrt{2} I_{r k} \cos \left[\left(\omega+k \omega_{r}\right) t-\varphi_{r k}-120^{\circ}\right]\end{array}\right\}$

$i_{c, b}(t)=$

$i_{c}(t)+$

$\sum_{k=1}^{\infty}\left\{\begin{array}{c}\sqrt{2} I_{l k} \cos \left[\left(\omega-k \omega_{r}\right) t-\varphi_{l k}+120^{\circ}\right] \\ +\sqrt{2} I_{r k} \cos \left[\left(\omega+k \omega_{r}\right) t-\varphi_{r k}+120^{\circ}\right]\end{array}\right\}$

$\mathrm{Bu}$ akımlar motorun ani gücünde denklem 7'de görülen ilave bir bileşen oluşturacaktır.

$$
p(t)=3 V I \cos \varphi+3 V \sum_{k=1}^{\infty}\left[\begin{array}{c}
I_{l k} \cos \left(k \omega_{b} t+\varphi_{l k}\right) \\
-I_{r k} \cos \left(k \omega_{b} t-\varphi_{r k}\right.
\end{array}\right]
$$

$p(t)=P+\Delta p_{b}(t)$

Bu bağıntıdan da görüldüğü gibi kırık rotor çubuğu arızasında kayma frekansına bağlı olarak farklı genlikte ve frekanslarda bileşenler meydana gelmektedir. Ayrıca, kırık rotor çubuğu arızaları motorun hava aralığındaki akıda denklem 8'deki eşitlik ile ifade edilen farklı frekanslardaki bileşenlerin oluşmasına neden olmaktadır [39].

$f_{k}=f\left[\left(\frac{k}{p}\right)(1-s) \mp s\right]$

Burada $\mathrm{f}$ şebeke frekansını, $\mathrm{k}$ harmonik derecesini, $\mathrm{p}$ çift kutup sayısını ve s kaymayı göstermektedir. Yukarıdaki bağıntılardan da görüldüğü gibi, kırık rotor çubuğu arızaları asenkron motorların hava aralığında motorun kutup sayısına bağlı olarak bir bileşen oluşturmakta, bunun sonucunda da ani güçte kaymaya göre değişen farklı frekanslarda bileşenler ortaya çıkmaktadır. Dolayısıyla motorun ani gücünde ortaya çıkan farklı frekans bandındaki bileşenlerin gözlenmesi arızanın oluşup oluşmadığının bir göstergesi olacaktır. 


\section{GÜÇ TABANLI ARIZA TESPIT ALGORITMASI (POWER BASED FAULT DETECTION ALGORITHM)}

Kırık rotor çubuğu arızaları ani güçte farklı frekans bileşenleri oluşturduğundan, yeni geliştirilen arıza tespit algoritmasında ilk önce üç fazlı ani gerilim ve akım değerlerinden hesaplanan ani güçteki frekans bileşenlerinin genliği denklem 9'daki bağıntıyla desibel cinsinden bulunur.

$X(f)=F\{x(t)\}$

Çift kutup sayısı 2 olan asenkron motorlarda mekanik dengesizliklerde ani güçte yaklaşık $25 \mathrm{~Hz}$ 'lik bileşen meydana geldiğinden [13], mekanik dengesizlik ile kırık rotor çubuğu arızalarını birbirinden ayırmak için $100 \mathrm{~Hz}$ 'lik frekans merkez olmak üzere bu frekansın her iki tarafinda maksimum kayma frekansı bandı aralığında enerji yoğunluğu denklem 10 kullanılarak hesaplanır.

$E_{b}=\sum_{n=-b}^{b}|x(n)|^{2}$

Motorun ani gücünün $100 \mathrm{~Hz}$ merkez frekansın etrafındaki frekans bileşenlerinin enerji yoğunluğundaki değişimin \% 20'den büyük olması durumunda kırık rotor çubuğu arızasının olduğu tespit edilir ve uyarı işareti verilir. Kayma frekansının en fazla $10 \mathrm{~Hz}$ olabileceği düşünülerek enerji yoğunluğu hesabı için 90-110 Hz aralığındaki frekans bileşenleri kullanılmıştır. Geliştirilen güç tabanlı yeni kırık rotor çubuğu arızası tespit algoritmasının akış diyagramı Şekil 1'de gösterilmiştir.

\section{DENEYSEL ÇALIŞMALAR (EXPERIMENTAL STUDIES)}

Geliştirilen güç tabanlı kırık rotor çubuğu arızası tespit algoritmasının doğruluğunu test etmek amacıyla Şekil 2'de gösterilen deney sistemi kurulmuştur. Deneysel çalışmalarda kullanılan $3 \mathrm{~kW}$ gücünde
220/380 V 4 kutuplu sincap kafesli üç fazlı asenkron motor DC generatör ile yüklenmiştir. Farklı yüklenme durumları DC generatörün uyarma akımı ve çıkışına bağlı dirençlerden oluşan yükler değiştirilerek oluşturulmuştur. Algoritma için gerekli olan gerilim ve akımlar transformatörler ile düşürüldükten sonra veri toplama kartı için uygun olan gerilim seviyesine düşürülmüştür.

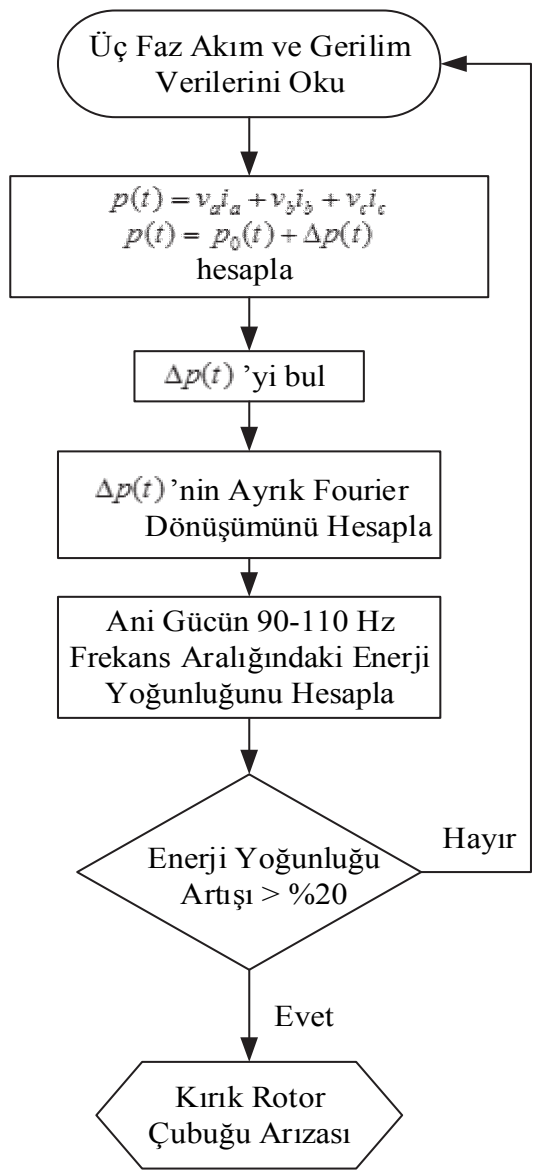

Şekil 1. Geliştirilen kırık rotor çubuğu arızası tespit algoritmasının akış diyagramı (Flowchart of the proposed broken rotor bars fault detection algorithm)

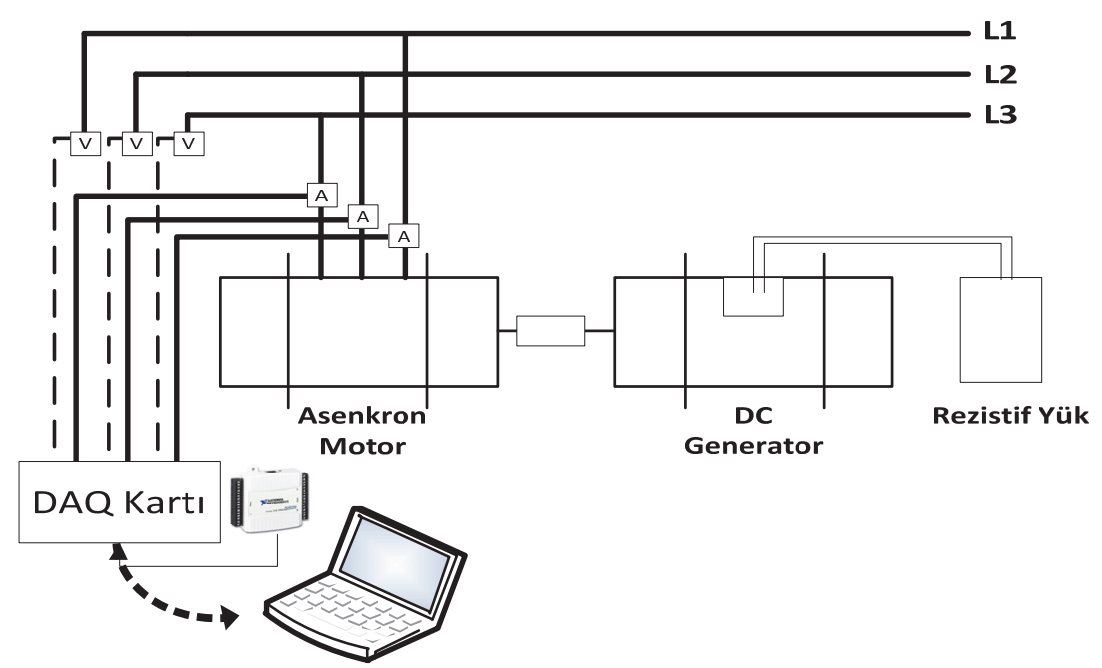

Şekil 2. Deney düzeneğinin bağlantı şeması (Connection diagram for experimental studies) 


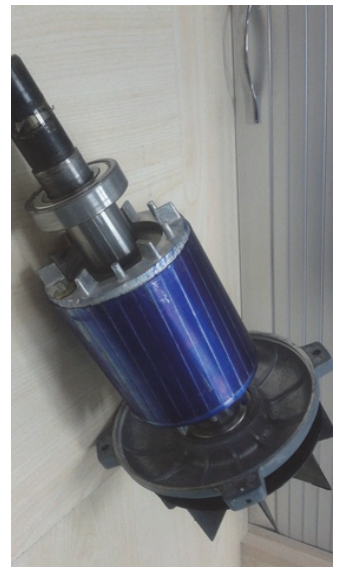

a)

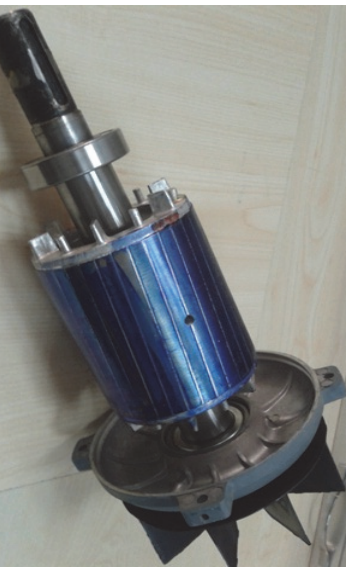

b)

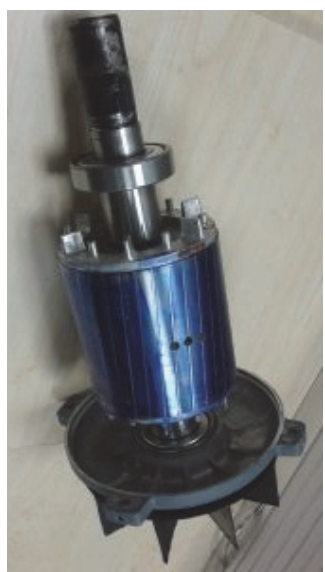

c)

Şekil 3. Kırık rotor arızasının oluşturulması a) Sağlam rotor b) Bir çubuğu kırık rotor c) Üç çubuğu kırık rotor (Creation of broken rotor bars faults a) Healty rotor b) One broken bar rotor c) Three broken bars rotor

Analog işaretlerin sayısala dönüştürülmesi için NI6251 veri toplama kartı kullanılmış ve ani güçteki çok yüksek frekanslı bileşenleri görebilmek için örnekleme frekansı $10 \mathrm{kHz}$ seçilmiştir. Deneysel çalışmalarda rotorda kırık oluşturmak amacıyla, Şekil 3'de görüldüğü gibi $5 \mathrm{~mm}$ çapında delik açılmıştır. Algoritmanın performansı sağlam durum, bir rotor çubuğu kırık durum ve üç rotor çubuğu kırık durum için test edilmiştir. Geliştirilen algoritmanın diğerlerine göre üstünlüğü yaygın olarak kullanılan akım imza analizi ile diğer güç tabanlı algoritmalar ile karşılaştırılarak gösterilecektir. Ani güçteki frekans bileşenlerini yüksek hassasiyette bulabilmek için 1s'lik pencere halinde ani güç değerleri kullanılmıştır. Asenkron motorun arızasız durumda \% 100 yüklü iken akım imza analizi ile çektiği güçteki frekans bileşenleri sırasıyla Şekil 4 ve Şekil 5'te görülmektedir. Akım imza analizinde akımdaki şebeke frekansının yanındaki bantlar beklenildiği gibi görülmemektedir. Ani güçte mekanik kaplin bağlantısındaki simetrisizlikten dolayı az da olsa yaklaşık $25 \mathrm{~Hz}$ 'lik bileşen ve motor yapısı ile şebeke geriliminin çok az da olsa dengesiz olmasından dolayı 100 Hz'lik bileşen görülmektedir. $\mathrm{Bu}$ değerler arızanın varlığını söyleyebilecek kadar büyük olmayıp, normal çalışmada görülebilecek büyüklüktedir ve $100 \mathrm{~Hz}$ 'in etrafinda yan bantlar oluşmamıștır. Arıza tespit algoritmalarının minimum etkiyi oluşturan arızalarda dahi doğru olarak çalışmaları gerekir. Rotor çubuğu kırık motor arızaları için tespiti en zor koşul bir çubuğu kırık ve yüksüz durumdur. Şekil 6'da bir rotor çubuğu kırık asenkron motorun akım imza analizi görülmektedir. Şekilden de görüldüğü gibi akımın $50 \mathrm{~Hz}$ 'lik bileşeninde yan bantlar oluşmamıștır. Bir rotor çubuğu kırık durum için ani güçteki frekans bileşenleri Şekil 7'de görülmektedir. Kayma frekansına yakın frekanslarda bir bileşenin oluşmamasına rağmen, 90-110 Hz frekans aralığındaki enerji yoğunluğunda sağlam duruma göre artış \% 28,03 kadar arttığı hesaplanmış ve arızanın oluştuğunun göstergesi kabul edilen \% 20'lik eşik değer aşıldığından arıza doğru olarak tespit edilmiştir.

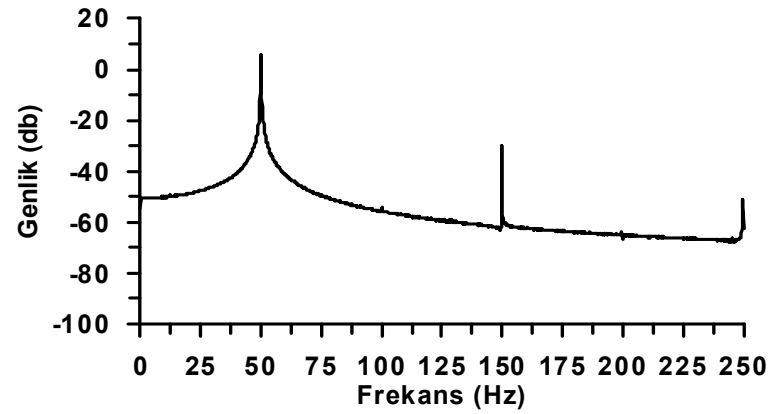

Şekil 4. Sağlam motor \% 100 yüklü durum için akım imza analizi (Current signature analysis for healty motor with $100 \%$ loaded condition)

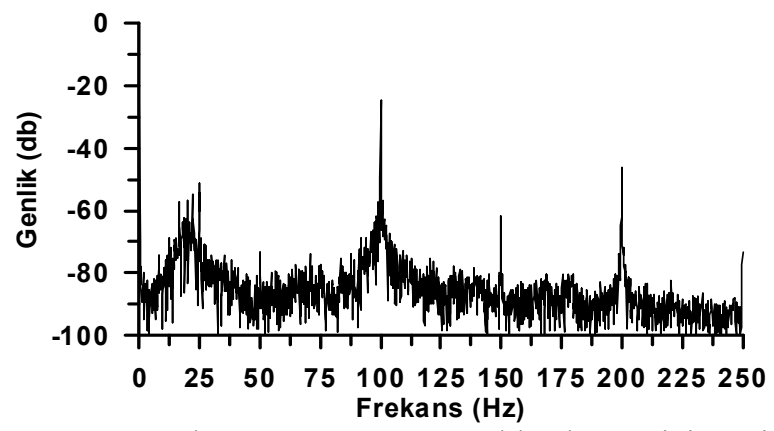

Şekil 5. Sağlam motor \% 100 yüklü durum için ani güçteki frekans bileşenleri (Instantaneous power frequency components for healty motor with $100 \%$ loaded condition)

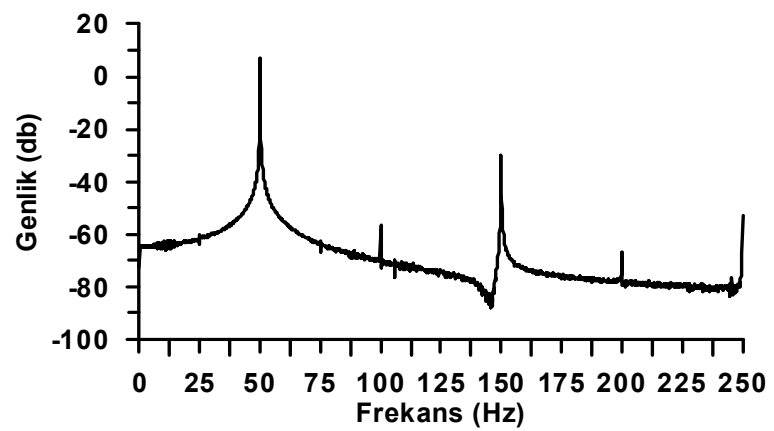

Şekil 6. Bir rotor çubuğu kırık motor yüksüz durum için akım imza analizi (Current signature analysis for one broken rotor bar with no load condition) 


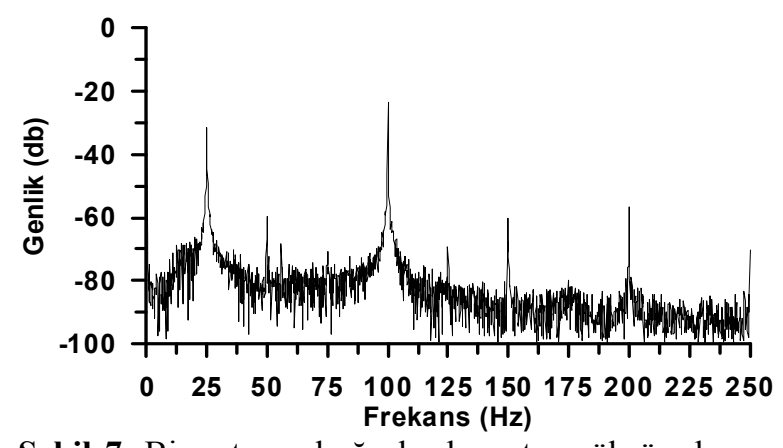

Şekil 7. Bir rotor çubuğu kırık motor yüksüz durum için ani güçteki frekans bileşenleri (Instantaneous power frequency components for one broken rotor bar with no load condition)

Üç rotor çubuğu kırık arızası oluşması ve \% 100 yüklenme durumu için akım imza analizi Şekil 8'de ve ani güçteki frekans bileşenleri Şekil 9'da verilmiştir. Akım imza analizi bu arıza durumunu da tespit edemezken, $100 \mathrm{~Hz}$ etrafındaki enerji yoğunluğunda büyük artışla arıza tespit edilmiştir. Ayrıca güçteki kayma frekansının iki katındaki bileşende de önemli derecede artış olmamış ve diğer güç tabanlı algoritmalarla arıza tespit edilememiştir.

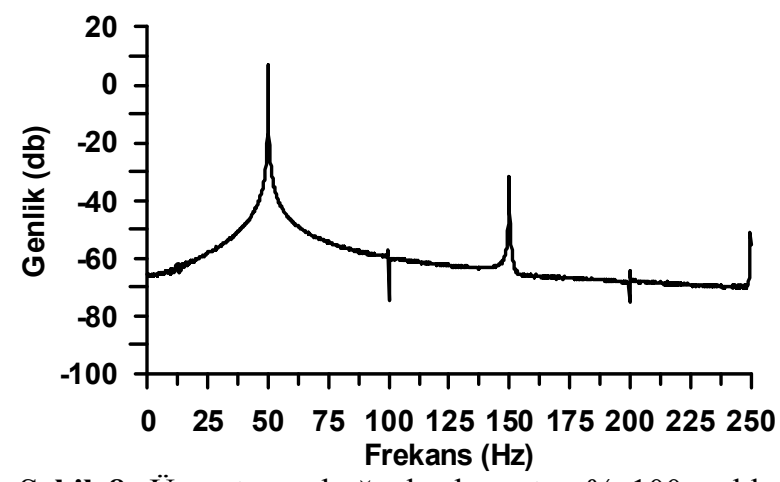

Şekil 8. Üç rotor çubuğu kırık motor \% 100 yüklü durum için akım imza analizi (Current signature analysis for three broken rotor bars with $100 \%$ loaded condition)

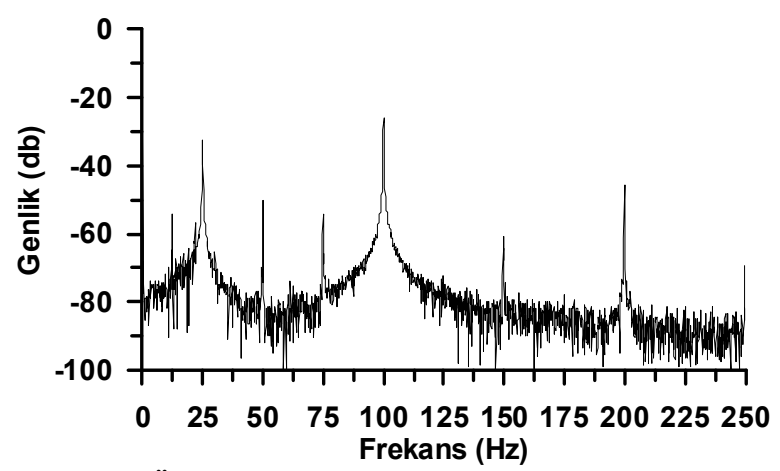

Şekil 9. Üç rotor çubuğu kırık motor \%100 yüklü durum için ani güçteki frekans bileșenleri (Instantaneous power frequency components for three broken rotor bars with 100 $\%$ loaded condition)

Geliştirilen algoritmanın performansı asenkron motorun çok faklı çalışma durumları için test edilmiştir. Şekil 10'da sağlam durum, sağlam \% 10 dengesizlik durumu, bir kırık çubuklu ve üç kırık çubuklu durum için faklı yüklenmelerde algoritmanın yanıtı görülmektedir. Sağlam motorun beslendiği üç fazlı gerilim kaynağında bir faza ait gerilimde \%10 kadar düşük gerilim verilerek bir dengesizlik oluşturulduğunda motorun ani gücünde $100 \mathrm{~Hz}$ frekanslı bileşen beklendiği gibi deneysel çalışmalar sonucunda görülmüştür. Fakat bu bileşen sadece 100 $\mathrm{Hz}$ frekansında olduğundan ve yan bantlarda ilave bileşenler olmadığından enerji yoğunluğu değerinin bir çubuk arızası durumundan daha az olduğu tespit edilmiştir. Motorun çektiği gücün 90-110 Hz aralığındaki enerji yoğunluğunda yüklenme ile belirgin değişiklik olmamakla birlikte, rotor çubuğu arızasının derecesine göre önemli artışlar olmuştur. Deneysel çalışmalar göstermiştir ki, geliştirilen arıza tespit yönteminin uygulanmasıyla motorun sağlam fakat anormal çalışma durumları ile yüksüz durum da dahil olmak üzere, kırık rotor çubuğu arıza durumları birbirinden kolaylıkla ayrilabilmektedir.

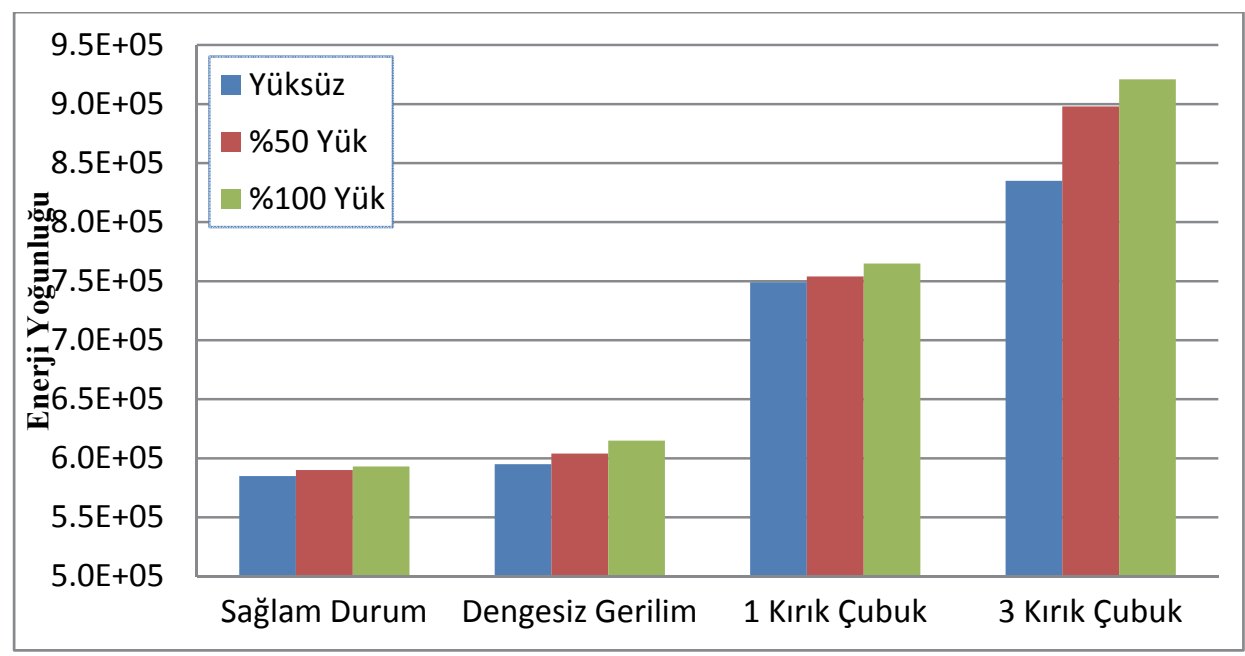

Şekil 10. Geliştirilen algoritmanın farklı çalışma durumları için yanıtı (Responses the proposed algorithm for different working conditions) 


\section{SONUÇLAR (CONCLUSIONS)}

Bu çalışmada üç fazlı asenkron motorlardaki kırık rotor çubuğu arızalarını tespit etmek için güç tabanlı yeni bir algoritma geliştirilmiştir. Dengeli üç fazlı gerilim kaynağından beslenen sağlam üç fazlı asenkron motorun çektiği ani güç sabit olup, aktif güç ile aynı değerdedir. Motorda mekanik veya elektriksel bir arızanın oluşması durumunda güçte farklı frekanslarda bileşenler oluşmaktadır. Yapılan bilimsel çalışmalardan elde edilen sonuçlar göstermiştir ki, kırık rotor çubuğu arızası motor hava aralığında dengesizliğe neden olmakta ve bu dengesizlik motorun ani gücünde baskın olarak $100 \mathrm{~Hz}$ civarındaki bant aralığında olmak üzere rotor frekansına bağlı olarak az da olsa rotor frekansının katları olan diğer bileşenlerin de ortaya çıkmasına neden olmaktadır. Ani güçte ortaya çıkan ve yük dengesizliğinde veya mekanik arızalarda görülmeyen bu baskın bileşenler kırık rotor çubuğu arızasını tespit etmek için önemli bir parametre olmuştur.

Kutup sayısına bağlı olarak motorun çektiği güçte ortaya çıkan bu frekans bileşenlerinin enerji yoğunluğu rotor çubuk arızasının varlığı ve derecesi hakkında bilgi vermektedir. Önceki yillarda birçok araştırma yapılmış olan akım imza analizi yönteminde stator akımının frekans spektrumundaki $(1 \pm 2 \mathrm{~s}) \mathrm{f}$ bileşenine bakılmasıyla arızanın varlığı ile yük dengesizliği birbirinden tam olarak ayırt edilememekteydi. Akım tabanlı yöntemlerin hızlı değişen yüklerde ve mekanik arızalarda güvenilir olmaması sonucu birçok yöntem geliştirilmiştir. Geliştirilen yöntemlerin çok fazla matematiksel işlem gerektirmesi ve mekanik arızalarda etkin biçimde çalışmaması sonucunda bu yöntemlerin pratik olarak bir üründe kullanılamaması bir dezavantaj olmuş ve bilgisayar kullanılarak geliştirilen sistemlerde de sürekli olarak bir uzman kişinin durumu gözlemesi zorunluluğu ortaya çıkmıştır.

Geliştirilen kırık rotor çubuğu arızası tespit algoritmasının performansını test etmek amaciyla deneysel çalışmalar yapılmıştır. Motorun sağlam olduğu durumda ani gücün içerdiği frekans bileşenlerinden $100 \mathrm{~Hz}$ 'in az da olsa bulunması beslendiği gerilimin tamamen dengeli olmaması ve motordaki bazı yapısal özelliklerden kaynaklandığı ve bu değerin normal olduğu görülmüştür. Ayrıca, motorun beslendiği gerilimin \% 10 dengesiz olması durumunda da dengesizlik ile bir rotor çubuğu kırık durumu birbirinden kolaylıkla ayırt edilmektedir. Bir kırık rotor çubuğu arızası ve boşta çalışma durumu arızayı tespit edebilmek için en zor durum olup, ani güçteki 90-110 Hz aralığındaki frekans bileşenlerinin enerji yoğunluğunda motorun sağlam ve yüksüz durumuna göre \% 28,03 kadar bir artış olmuş ve arıza başarıyla tespit edilmiştir. Güç tabanlı geliştirilen bu yöntem diğer yöntemlere göre daha az işlem gerektirdiğinden ve arızanın oluştuğunun tespit edilmesinde somut bir gösterge olduğundan, endüstrideki motorlarda kullanılan mikroişlemci tabanlı sistemlere kolaylıkla ilave edilebilir. Büyük güçlü motorlarda da performansı test edildikten sonra geliştirilen algoritma çok fonksiyonlu koruma ve izleme sistemlerinde ilave özellik olarak kullanılabilir.

\section{TEŞEKKÜR (ACKNOWLEDGEMENT)}

Deneysel çalışmalar Sakarya Üniversitesi Bilimsel Araştırma Projeleri Komisyon başkanlığı tarafindan 20105002021 numaralı proje kapsamında desteklendiğinden, Sakarya Üniversitesi BAPK başkanlığına ve Sakarya Üniversitesi Rektörlüğüne teşekkür ederiz.

\section{KAYNAKLAR (REFERENCES)}

1. Haji, M. ve Toliyat, H.A., "Pattern recognition-a technique for induction machines rotor broken bar detection", IEEE Trans. On Energy Conversion, Cilt 16, No 4, December 2001.

2. Williamson, S. ve Smith, A.C., "Steady state analysis of 3-phase cage motors with rotor broken bar and end ring faults", IEEE Proc.-B, Cilt 129, No 3, 93-100, 1982.

3. Deleroi, W., "Squirrel cage motor with broken bar in the rotor-physical phenomena and their experimental assessment", Proceeding of International Conference on Electrical Machines, September 1982.

4. Kliman, G.B., and at al, "Noninvasive detection of broken rotor bars in operating induction machines", IEEE Trans. on Energy Conversion, Cilt 3, No 4, 873-879, 1988.

5. Benbouzid, M.E.H., "A review of induction motors signature analysis as a medium for faults detection", IEEE Trans. on Ind. Electron., Cilt 47, No 5, 2000.

6. Benbouzid, M.E.H. ve Kliman, G. B., "What stator current processing-based technique to us efor induction motor rotor faults diagnosis", IEEE Trans. on Energy Conv., Cilt 18, No 2, 2003.

7. Bellini, A., and et al., "Advances in diagnostic techniques for induction machines", IEEE Trans. on Ind. Electron., Cilt 55, No 12, 41094126, 2008.

8. Wu, L., Habetler, T.G. ve Harley, R.G., "A review of separating mechanical load effects from rotor faults detection in induction motors", IEEE Int. Symposium on Diagnostics for Electric Machines, Power Elec. and Drives, Poland, 2007.

9. Bloot, M., and et al., "On-line monitoring of mechanical faults in variable-speed induction motor drives using the Wigner distribution", IEEE Trans. on Ind. Electron., Cilt 55, No 2, 2008. 
10. Siddiqui, K.M., Giri, V.K., "Broken rotor bar fault detection in induction motors using transient current analysis", International Journal of Electronics \& Communication Technology, Cilt 2, No 4, December 2011.

11. Aydın, İ., Karaköse, M. ve Akın, E., "Zaman serisi veri madenciliği ve destek vektör makinalar kullanan yeni bir akıllı arıza sınıflandırma yöntemi”, Journal of the Faculty of Engineering and Architecture of Gazi University, Cilt 23, No 2, 431-440, 2008.

12. Aydın, İ., Karaköse, M. ve Akın, E., "Negatif seçim tabanlı bulanık arıza teşhis modeli", Journal of the Faculty of Engineering and Architecture of Gazi University, Cilt 24, No 4, 745-753, 2009.

13. Bayır, R., Bay, Ö.F., "Marş motoru akım sinyalleri wavelet analiz sonuçlarının bulanık mantık ile sınıflandırılarak arıza tespiti”, Journal of the Faculty of Engineering and Architecture of Gazi University, Cilt 22, No 2, 363-374, 2007.

14. Ayaz, E., Öztürk, A., Şeker, S., Upadhyaya, B.R., "Fault detection based on continuous wavelet transform and sensor fusion in electric motors", The Int Journal for Comp. and Math in Electrical and Electronic Eng., Cilt 28, 454470, 2009.

15. Radhika, S., and et al., "Precise wavelet for current signature in $3 \phi$ IM", Expert Systems with Applications, Cilt 37, No 1, 450-455, 2010.

16. Siddiqui, K.M. ve Giri, V.K., "Broken rotor bar fault detection in induction motors using wavelet transform", IEEE conference on Computing Electronics and Electrical Technologies, India, 2012.

17. Schoen, R.R. ve Habetler, T.G., "Evaluation and implementation of a system to eliminate arbitrary load effects in current-based monitoring of induction machines", IEEE Trans. on Ind. Appl., Cilt 33, No 6, 1571-1577, Nov./Dec. 1997.

18. Cruz, S.M.A., "An active-reactive power method fort he diagnosis of rotor faults in three-phase induction motors operating under time-varying load conditions", IEEE Trans. on Energy Conversion, Cilt 27, No 1, 71-84, March 2012.

19. De Angelo, C.H., Bossio, G.R. ve Garcia, G.O., "Discriminating broken rotor bar from oscillating load effects using the instantaneous active and reactive Powers", IET Electric Power Applications, Cilt 4, No 4, 281-290, 2010.

20. Cruz, S.M.A. ve Cardoso, A.J.M., "Rotor cage fault diagnosis in operating three-phase induction motors, under the presence of time-varying loads", European Conf. Power Elec. Appl., Graz, Austria, 2001.

21. Cruz, S.M.A. ve Cardoso, A.J.M., "Further developments on the use of the synchronous reference frame current Park's vector approach",
Proc. IEEE Int. Symp. Diagnostics Electr. Mach., Italy, 2001.

22. Cardoso, A.J.M. ve et al., "Rotor cage fault diagnosis in induction motors by Park's vector approach", IEEE-IAS Annual Meeting, Orlando, 1995.

23. Nejari, M., Benbouzid, H., "Monitoring and diagnosis of induction motors electrical faults using a current Park's vector pattern learning approach", IEEE Trans. on Ind. Appl., Cilt 36, No 3, 2000.

24. Güran, F. ve Eren, L., "Motor akım imza analizinde park dönüşümüyle temel harmonik bastırımı", EMO Bilimsel Dergi, Cilt 2, No 3, 45-49, 2012.

25. Seera, M., Lim, C.P., Ishak, D., Singh, H., "Fault detection and diagnosis of induction motors using current signature analysis and hybrid FMMCART model", IEEE Trans. on Neural Netw. And Learning Systems, Cilt 23, No 1, 2012.

26. Akar, M., Çankaya, İ., "Broken rotor bar fault detection in inverter-fed squirrel cage induction motors using stator current analysis and fuzzy logic", Turk J Eng \& Comp Sci., Cilt 20, No 1, 1077-1089, 2012.

27. Çalış, H., Çakır, A., "Rotor bar fault diagnosis in three phase induction motors by monitoring fluctuations of motor current zero crossing instants", Electric Power System Research, Cilt 85, 385-392, 2006.

28. Çalış, H., Çakır, A., "Experimental study for sensorless broken bar detection in induction motors", Energy Conversion \& Management, Cilt 49, 854-862, 2008.

29. Alarcon, V.C. and et al, "Vibration transient detection of broken rotor bars by $\mathrm{PSH}$ sidebands", IEEE Trans. on Ind. Appl., Cilt 49, No 6, 2013.

30. Liu, Z. and et al., "Online rotor mixed fault diagnosis way based on spectrum analysis of instantaneous power in squirrel cage induction motors", IEEE Trans. on .Energy Conversion, Cilt 19, No 3, 485-490, September 2004.

31. Eltabach, M., Charara, A., Zein, I., "A comparison of external and internal methods of signal spectral analysis for broken rotor bars detection in induction motors", IEEE Trans. on Ind. Electr., Cilt 51, No 1, 107-121, Feb. 2004.

32. Drif, M. ve Cardoso, A.J.M., "Discriminating the simultaneous occurence of three-phase induction motor rotor faults and mechanical load oscillations by the instantaneous active and reactive power media signature analyses", IEEE Trans. on Ind. Electr., Cilt 59, No 3, Mach 2012.

33. Küçüker, A. ve Bayrak, M., "Detection of Mechanical Imbalances of Induction Motors with Instantaneous Power Signature Analysis" J Electr Eng Technol, Cilt 8, No 5, 1116-1121, 2013. 
34. Gyftakis, K.N., and et al., "A novel approach for broken bar fault diagnosis in induction motors through torque monitoring", IEEE Trans. on Energy Conversion, Cilt 28, No 2, June 2013.

35. Nemec, M., and et al., "Detection of broken bars in induction motor through the analysis of supply voltage modulation", IEEE Trans. on Ind. Appl., Cilt 57, No 8, 2879-2888, August 2010.

36. Arabac1, H., Bilgin, O., " Detection of rotor bar faults by using stator current envelope", Proceedings of the World Congress on Engineering, London, 2011.
37. Usta, Ö., Bayrak, M., Redfern, M.A., "A new digital relay for generator protection against asymmetrical faults", IEEE Trans. on Power Delivery, Cilt 17, No 1, 54-59, January 2002.

38. Küçüker, A., "Asenkron motorlar için çok fonksiyonlu koruma algoritması tasarımı", Doktora Tezi, Sakarya Üniversitesi Fen Bilimleri Enstitüsü, 2013.

39. Kliman, G.B. ve Koegl, R.A., "Noninvasive detection of broken rotor bars in operating induction motors", IEEE Trans. on Energy Conversion, Cilt 3, No 4, December 1988. 
